\title{
Perceptions of students after implementing peer instruction in an introductory physics course
}

\author{
Nicolás Budini ${ }^{1,2^{*}}$ D, Luis Marino ${ }^{3}$, Ricardo Carreri ${ }^{1}$, Cristina Cámara ${ }^{1,4}$ and Silvia Giorgi ${ }^{1}$
}

\author{
* Correspondence: nicolas.budini@ \\ santafe-conicet.gov.ar \\ ${ }^{1}$ Facultad de Ingeniería Química, \\ Universidad Nacional del Litoral, \\ Santiago del Estero 2829, \\ S3000AOM Santa Fe, Argentina \\ ${ }^{2}$ Instituto de Física del Litoral \\ (UNL-CONICET), Güemes 3450, \\ S3000GLN Santa Fe, Argentina \\ Full list of author information is \\ available at the end of the article
}

\begin{abstract}
In the present work we carried out a qualitative educational research to assess the perceptions of a group of students that attended (weekly and non-mandatory) complementary classes of a physics course during 2017. In these classes the teaching method called peer instruction (PI) was implemented, which involves collaborative learning among students. From the students' responses to a simple questionnaire we assessed some basic aspects of these classes from which we can conclude that, in the first place, students considered that PI had positively influenced their comprehension of physical concepts and that, secondly, they positively valued the activities performed and the dynamics of these classes. These results, which are part of a series of previous works that have been published elsewhere, are relevant in a context were active and collaborative learning strategies are practically non-existent and push us to continue and broaden the implementation of this and other active learning methods in physics courses.
\end{abstract}

Keywords: Physics education research, Undergraduate level, Active learning, Peer instruction, Collaborative learning, Students' perceptions

\section{Introduction}

From systematic results of physics education research (PER), that have been broadly gathered during the past decades, it is known that students have general inherent difficulties in understanding concepts involved in physics introductory courses (Byun and Lee, 2014). Therefore, with the aim of improving students' conceptual skills, diverse methods have been developed to actively engage students in their own learning process. An interesting review and cognitive foundations of different active learning approaches for physics instruction can be found in Redish (2003) and Meltner and Thornton (2012). Among these, the peer instruction (PI) methodology (Mazur, 1997), which has been successful in American universities, is simple to implement and easy to adapt to different educational contexts.

Mazur found that although many students give inadequate answers to simple qualitative questions about a concept they are, in general, good at solving quantitative problems related to it. This fact made him question about his teaching and evaluation strategies, since this result poses the risk that students approve a physics course without having an acceptable understanding of the basic physical principles, laws and concepts that they are expected to learn. Considering his study, he suggested that a better

(c) The Author(s). 2019 Open Access This article is distributed under the terms of the Creative Commons Attribution 4.0 International License (http://creativecommons.org/licenses/by/4.0/), which permits unrestricted use, distribution, and reproduction in any medium, provided you give appropriate credit to the original author(s) and the source, provide a link to the Creative Commons license, and indicate if changes were made. 
conceptual understanding would unquestionably lead to a better performance of students, both in qualitative and quantitative problem solving.

With this evidence, teachers should not be satisfied when a student simply knows how to plug numbers into equations in a given situation (which in generally is done by rote memorising), how to solve a differential equation or how to state a physical law. The responsibility of a physics teacher should push him to an effective training of students which is now possible by implementing diverse active learning strategies available (and new strategies that are yet to be developed).

The aim of this work was to qualitatively assess the perceptions of students after being engaged in active learning through the PI strategy, as a complement of traditional lectures. In other words, we sought to gather students perceptions and ideas about how the active learning activities they went through impacted on them (in our educational context this kind of activities are far from common). For this, the results obtained from an opinion survey, answered by students who attended (non-mandatory) complementary classes (CC) where PI was implemented, were reported and analyzed. The attendants were 29 students who fulfilled all necessary requirements to finish a first physics course; some of them approved the course by mid-term exams, others approved it through a final exam and others did not approve until writing this article. All students that were involved in this research did it under their own will.

This work together with a series of previous works that have been published elsewhere (see, for example, Budini et al., 2016; 2017) have marked us the way to make a more systematic use of these new teaching tools. It is worth highlighting that physics teaching in our context possesses an enormous inertia to switch to more efficient teaching and learning schemes. Therefore, these studies serve us as a valuable feedback to improve and broaden our implementation of active learning strategies in physics courses.

\section{Theoretical framework and objectives}

The results derived from worldwide PER results have shown strong evidence that active learning strategies improve students' conceptual knowledge (Ausubel, 1968; Redish, 2003; Kattmann, 2008; Treagust and Duit, 2009; Meltzer and Thornton, 2012; Freeman et al., 2014). These strategies share the vision that the learning process in physics should conduct to a construction of a clear, stable and organized body of knowledge, allowing students to use it in different situations and contexts while acquiring new knowledge in the same field.

The PI strategy involves the concept of collaborative learning (CL) (Crouch and Mazur, 2001). This modality points to improve the understanding of a topic by students working in small groups where different conceptual skills inevitably exist among them. The CL provides a favorable framework for building knowledge and it is based on conceiving education as a socio-constructive process (Vygotski, 1980). CL-based classes are more dynamic than traditional ones, and students learn actively in a more relaxed and flexible environment. It is well known that CL helps students to reach the mutual achievement of a new level of knowledge and satisfaction (Calzadilla, 2002; Martín del Pozo, 2017; Navío-Marco, 2019).

In the context of a first physics course, the PI modality has started to be implemented during the above mentioned non-mandatory $\mathrm{CC}$; the students are asked to read a brief written material (class notes) before attending the class. 
These weekly classes last for about two hours and are held right after the traditional lectures in which the topic to be addressed is developed. It should be noted that for effective PI it is necessary that students have had a first contact with the topic, in order to focus attention on the basic physical concepts or those that offer greater comprehension difficulties. The design of these classes considers the following key points:

(1) identify the topics that result more difficult for students and choose a few physical concepts related to those topics to reinforce in the CC;

(2) design interactive and motivating collaborative activities around those few concepts;

(3) formulate conceptual questions (Mazur, 1997) around the concepts of interest, so students can answer at the moment (Budini et al., 2016; 2017).

A first instance of the $\mathrm{CC}$ deals with a revision of the concepts to be addressed during a brief exposition by the teacher. PI begins presenting students conceptual questions about the topic of interest and concept relations that they should reinforce. The questions present multiple choices, where only one is correct. As students answer these questions, they immediately receive feedback from the teacher. This aspect is very important during PI in order to guide the student through understanding why one of the options is correct and not the others. In this way we seek to generate motivation in the students since they can confront their own ideas with the feedback they receive and clarify the concepts at the moment. It is important to highlight that our approach intends to mimic as close as possible the PI implementation of Mazur.

Descriptions of the activities developed in the CC can be found in Budini et al. (2016; 2017). Since success of PI depends on the quality and relevance of the selected conceptual questions, they are chosen from those elaborated by Mazur (1997) or, otherwise, they are designed taking into account the following criteria (Beatty et al., 2006):

a) they must focus on a single concept,

b) their answers should not be selected by replacing numerical values in equations,

c) they should have enough answering options (multiple choices),

d) they should be written in an unambiguous and clear fashion,

e) they should be of moderately difficult.

The activities implemented during the $\mathrm{CC}$ at our institution are developed according to the following stages for each conceptual question addressed, as described in Budini et al. (2016; 2017):

(1) the teacher presents the question and its possible answers using a projector and reads it loudly, in order to avoid confusions about the statement;

(2) students access the question through a web-form using their smartphones;

(3) during two minutes, students are asked to individually analyze the question and register their guess in the web-form considering also their confidence level (very sure, still thinking and not sure);

(4) during five more minutes students start discussing with their neighbors (peer-to-peer discussion) about which option they have chosen and why (here they elaborate the arguments that led them to select certain option); 
(5) after this discussion, students are asked to reconsider their previous guess and reenter in the web-form both the answer and confidence level, so those who have changed their mind after discussion can modify their responses and confidence levels;

(6) the distribution of answers and confidence levels (before and after discussion) are shown to the class, prior to start a general discussion in order to deduce the correct answer and its foundation.

The discussion between students after their individual choices forces them to think and argument collaboratively (CL) about the problem, which gives them (and also the teacher) a way to assess the degree of understanding of the addressed concept.

The use of web-forms is very efficient to have an immediate panorama of the distribution of responses and confidence levels. It also allows teachers to quantify the effectiveness of the interaction among students. Besides the advantage of having immediate feedback, the possibility of registering the responses in a database is important for teachers in order to analyze how students answers change before and after the discussion stage. This allows getting a huge amount of information about the class dynamics during PI and favors a smart design of future activities in the physics course.

The experience of Mazur (1997) showed that through PI there is always an increase (and never a decrease) in the percentage of correct answers. In this direction, the same results were reached by Budini et al. (2016; 2017), but with some warnings. For example, teachers must be aware of the possibility that some students can change their correct answers to incorrect ones in the second stage.

Regarding the results obtained through PI, Mazur (1997) highlighted the numerous advantages of this strategy. The discussion among students after the first answer promote their active participation in the class. More importantly, students are not forced to assimilate the material presented to them, as they must reflect and put their thoughts into words. Sometimes, students are able to explain concepts to their peers more effectively than the teacher. This could be probably because students who understand the concept are aware of the difficulties involved in its interpretation and know exactly what should be emphasized in their explanation.

\section{Methodology}

In this work, a simple pre-structured opinion survey (see Additional file 1) was elaborated and implemented to qualitatively assess the perceptions of 29 students, which currently attend the second physics course (electricity and magnetism). All these students had previously attended the CC during the first physics course (mechanics) in 2017. It must be highlighted that these students met all necessary academic requirements to finish the first physics course.

The aim of the survey was assessing students' valuations regarding the usefulness of the CC, where we implemented PI. In particular we looked for personal perceptions about the activities developed during CC (that is, if PI activities were interesting, motivating, entertaining, confusing, boring, and/or complicated). In other words, the survey allowed us to evaluate students' perceptions about their own learning process engaged through the PI strategy. This methodology derives from studies addressed by different authors (Cortright et al., 2005; Giuliodori et al., 2006; Nicol and Boyle, 2003) about cognitive and affective perceptions of students in relation to the PI strategy. 


\section{Results and discussion}

In the following we present and discuss the results obtained from the survey (see Additional file 1). Figure 1 shows the proportion of assessed students that were in different situations regarding the approval of the first physics course: $45 \%$ of them approved through a final exam, $24 \%$ approved through a mid-term exam and $31 \%$ haven't approved yet.

Students were asked to assess the benefit obtained from attending the $\mathrm{CC}$, regarding the self-perceived improvement and understanding of physics concepts. The obtained answers are shown in Fig. 2, discriminated as a function of the students' approval of the course. It is observed that all students who approved through mid-term exams considered of great usefulness the teaching-learning proposal implemented in the CC. Those who approved through a final exam, and those that did not approve yet, considered CC to be quite useful. Finally, a small group stated that the proposal was not very useful. In general, most students valued the CC positively.

The students' perceptions regarding the activities developed during the $\mathrm{CC}$ were also assessed according to the following descriptors: interesting, motivating, entertaining, confusing, boring, complicated. The options available were: a lot, quite, a little, very little, nothing.

It can be observed that many of those who approved the subject by mid-term exams believed that the $\mathrm{CC}$ were quite interesting, motivating and entertaining, and considered them not confusing at all, very little boring and a little complicated. In turn, students who approved through a final exam considered that the CC were very and quite interesting. Most students pondered the activities as motivating and entertaining; a lower number of students felt that they were little or very little confusing. In addition, they answered that the classes turned out to be little, very little or not boring at all, and little or not complicated at all. Finally, students who did not approve yet felt mostly that these classes were quite interesting, motivating and entertaining, very little confusing, a

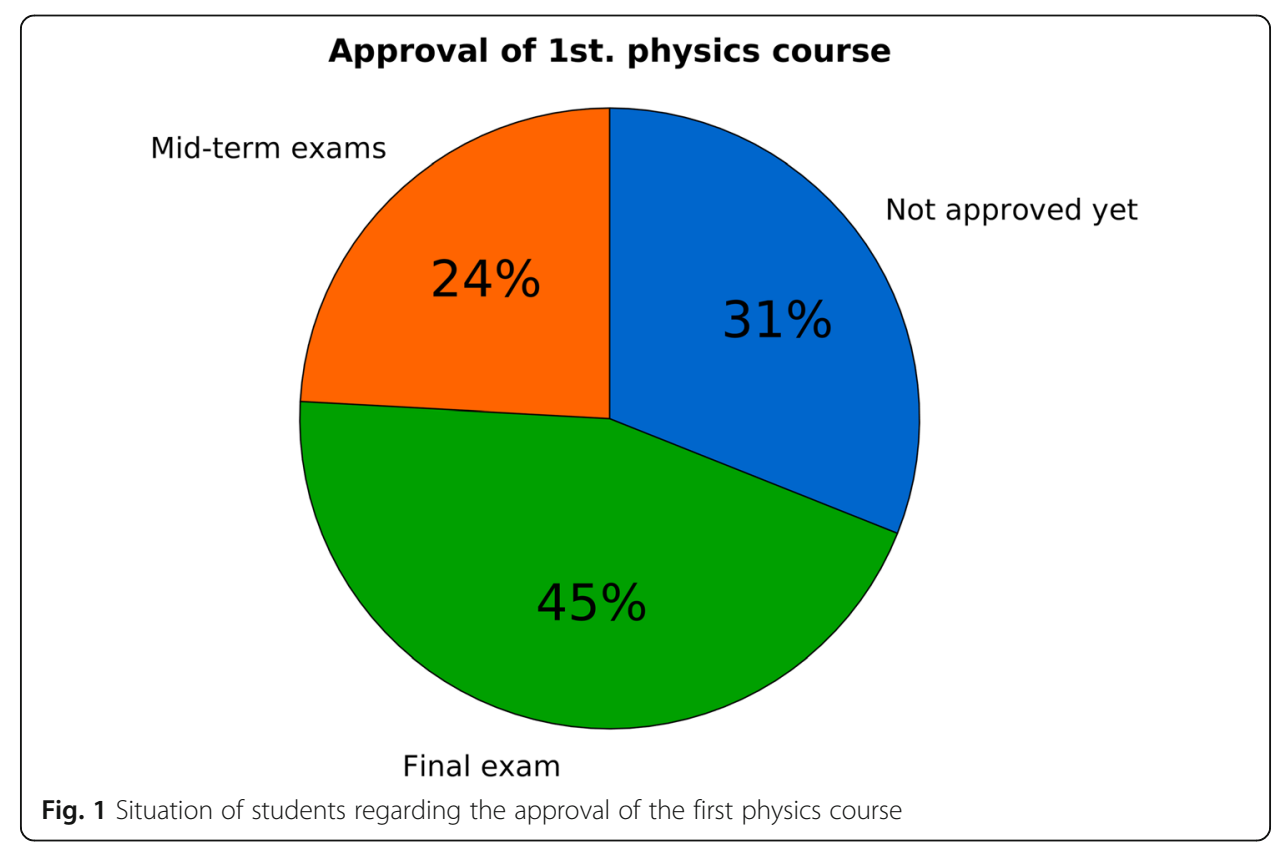



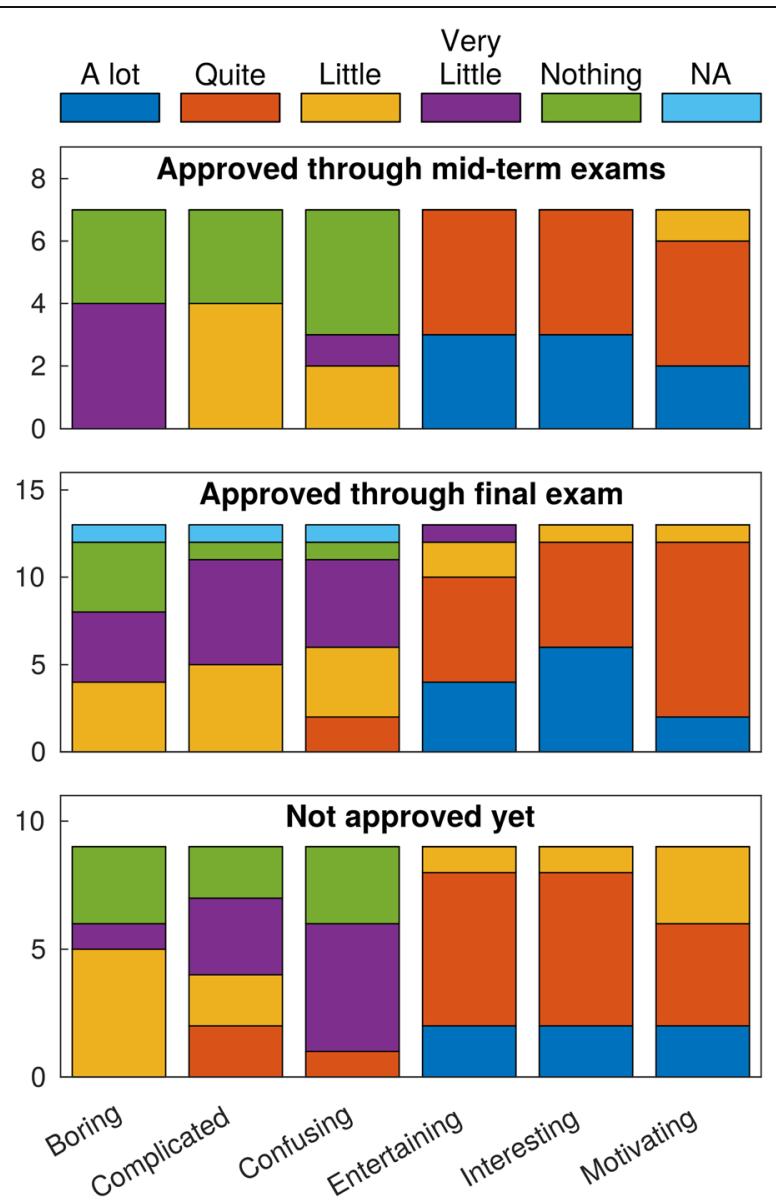

Fig. 2 Opinions of students about the contribution of the PI activities to their understanding of physics concepts: (top) students that approved through mid-term exams, (middle) students that approved through final exam and (bottom) students thatn didn't approve yet

little boring and a similar number of students felt that the classes were quite, little, very little or not complicated at all.

Summarizing the results presented above, Table I shows the evaluated aspects and the most frequent responses given by students, discriminated as a function of their situations regarding approval of the subject. It is clear that most students valued the $\mathrm{CC}$ as interesting, motivating, entertaining, little confusing, little boring and little complicated. With respect to the latter, it should be noted that only two students (which did not approve the course yet) considered that $\mathrm{CC}$ were quite confusing.

Table I Summary of most frequent students' opinions

\begin{tabular}{llll}
\hline & $\begin{array}{l}\text { Approved through } \\
\text { mid-term exams }\end{array}$ & $\begin{array}{l}\text { Approved through } \\
\text { final exam }\end{array}$ & Not approved yet \\
\hline Interesting & A lot - Quite & A lot - Quite & Quite \\
Entertaining & A lot - Quite & Quite & Quite \\
Motivating & Quite & Quite & Quite \\
Confusing & Nothing & Little - Very little & Very little \\
Complicated & Little & Little - Very little & Quite - Little - Very little - Nothing \\
Boring & Very little & Little - Very little - Nothing & Little \\
\hline
\end{tabular}


Finally, it is important to highlight that all students (except only one who did not answer the item) recommended the implementation of this kind of strategies in the second physics course.

\section{Conclusions}

The results presented in this work encourage teachers and researchers to continue, improve and broaden the implementation of active learning strategies in physics courses at our institution. Further work is being performed in order to extend these strategies in an environment where the systematic use of this kind of teaching practices are practically non-existent.

\section{Additional file}

Additional file 1. Survey elaborated and used for assessing students' perceptions regarding the implementation of peer instruction activities during their first physics course (mechanics).

Authors' contributions

All authors read and approved the final manuscript.

Funding

This work was funded by CAI + D N $50120150100122 \mathrm{LI}$ (UNL) project.

\section{Availability of data and materials}

The datasets used and/or analyzed during the current study are available from the corresponding author on reasonable request.

\section{Competing interests}

The authors declare that they have no competing interests.

\section{Author details}

${ }^{1}$ Facultad de Ingeniería Química, Universidad Nacional del Litoral, Santiago del Estero 2829, S3000AOM Santa Fe, Argentina. ${ }^{2}$ Instituto de Física del Litoral (UNL-CONICET), Güemes 3450, S3000GLN Santa Fe, Argentina. ${ }^{3}$ Facultad de Humanidades y Ciencias, Universidad Nacional del Litoral, Ciudad Universitaria, Paraje El Pozo, 3000 Santa Fe, Argentina. ${ }^{4}$ Facultad de Ciencias Agrarias, Universidad Nacional del Litoral, 86-Kreder 2805, 3080HOF Esperanza, Santa Fe, Argentina.

Received: 6 October 2019 Accepted: 26 November 2019

Published online: 12 December 2019

\section{References}

Ausubel, D. P., Novak, J. D., \& Hanesian, H. (1968). Educational psychology: A cognitive view. United States: Holt, Rinehart and Winston.

Beatty, I. D., Gerace, W. J., Leonard, W. J., \& Dufresne, R. J. (2006). Designing effective questions for c lassroom response system teaching. Am J Phys, 74, 31-39.

Budini, N., Giorgi, S., Sarmiento, L., Cámara, C., Carreri, R., Marino, L. and Gómez, C. (2016). Implementación de actividades colaborativas en las clases de Física del ciclo inicial universitario. Revista de Enseñanza de la Física 28(extra), pp. 187-95.

Budini, N., Giorgi, S., Sarmiento, L., Cámara, C. and Carreri, R. (2017). Actividades colaborativas sobre conceptos de mecánica en sistemas físicos no puntuales. Revista de Enseñanza de la Física 29(extra), pp. 287-96.

Byun, T., \& Lee, G. (2014). Why students still can't solve physics problems after solving over 2000 problems. Am J Phys., 82(9), 906-913.

Calzadilla, M. E. (2002). Aprendizaje colaborativo y tecnologías de la información y la comunicación. Rev Iberoam Educ, 1(10), $1-10$

Cortright, R. N; Collins, H. L. and DiCarlo, S. E. (2005). Peer instruction enhanced student meaningful learning: Ability to solve novel problems. Adv Physiol Educ, 29, 107-111.

Crouch, C. H., \& Mazur, E. (2001). Peer instruction: Ten years of experience and results. Am J Phys, 69, 970-977.

Freeman, S., Eddy, S. L., McDonough, M., Smith, M. K., Okoroafor, N., Jordt, H., \& Wenderoth, M. P. (2014). Active learning increases student performance in science, engineering, and mathematics. Proc. the Natl Acad Sci, 23(111), 8410-8415.

Giuliodori, M. J., Lujan, H. L., \& DiCarlo, S. E. (2006). Peer instruction enhanced student performance on qualitative problemsolving questions. Adv Physiol Educ, 30, 168-173.

Kattmann, U. (2008). Learning biology by means of anthropomorphic conceptions? In M. Hamman et al. (Eds.), Biology in context: Learning and teaching for the 21 century. London: Institute of Education, University of London.

Martín del Pozo, M., Basilotta Gómez-Pablos, V., \& García-Valcárcel Muñoz-Repiso, A. (2017). A quantitative approach to preservice primary school teachers' attitudes towards collaborative learning with video games: Previous experience with video games can make the difference. Int J Educ Technol High Educ, 14(1), 11. 
Mazur, E. (1997). Peer instruction. A User's manual. United States: Prentice Hall.

Meltzer, D. E., \& Thornton, R. K. (2012). Resource letter ALIP-1: Active-learning instruction in physics. Am J Phys, 80(6), 478-496.

Navío-Marco, J. and Solórzano-García, M. (2019). Student's social e-reputation ("karma") as motivational factor in MOOC learning. Interact Learn Environ, 0, 1-15.

Nicol, D. J., \& Boyle, J. T. (2003). Peer instruction versus class-wide discussion in large classes: A comparison of two interaction methods in the wired classroom. Stud High Educ, 28(4), 457-473.

Redish, E. F. (2003). Teaching physics: With the physics suite. Hoboken, NJ: John Wiley \& Sons

Treagust, D., \& Duit, R. (2009). Multiple perspectives of conceptual change in science and the challenges ahead. J Sci Math Educ Southeast Asia, 32(2), 89-104.

Vygotsky, L. S. (1980). Mind in society: The development of higher psychological processes. United States: Harvard University Press.

Publisher's Note

Springer Nature remains neutral with regard to jurisdictional claims in published maps and institutional affiliations.

Submit your manuscript to a SpringerOpen ${ }^{0}$ journal and benefit from:

- Convenient online submission

- Rigorous peer review

- Open access: articles freely available online

High visibility within the field

Retaining the copyright to your article

Submit your next manuscript at $>$ springeropen.com 